\title{
Female Overrepresentation in Low Back-Related Leg Pain: A Retrospective Study of the Autonomic Response to a Minimally Invasive Procedure
}

This article was published in the following Dove Press journal:

Journal of Pain Research

\author{
Elzbieta Skorupska $\mathbb{1}^{1}$ \\ Marta Jokiel ${ }^{1,2}$ \\ Michał Rychlik ${ }^{3}$ \\ Rafał Łochowski $\mathbb{1}^{4}$ \\ Małgorzata Kotwicka ${ }^{5}$ \\ 'Department of Physiotherapy, Poznan \\ University of Medical Sciences, Poznan, \\ Poland; ${ }^{2}$ Department of Orthopedics, \\ Traumatology and Hand Surgery Poznan \\ University of Medical Sciences, Poznan, \\ Poland; ${ }^{3}$ Department of Virtual \\ Engineering, Poznan University of \\ Technology, Poznan, Poland; \\ ${ }^{4}$ Department of Mathematics and \\ Mathematical Economics, Warsaw School \\ of Economics, Warsaw, Poland; \\ ${ }^{5}$ Department of Cell Biology, Poznan \\ University of Medical Sciences, Poznan, \\ Poland
}

Background: The newly proposed low back pain treatment requires case classification according to the pain mechanism (nociceptive, neuropathic or nociplastic) to determine the most effective therapeutic approach. However, there is a lack of objective tools for distinguishing these pain mechanisms. The aim of the study was to identify which symptoms, signs, and standard diagnostic parameters would allow predicting the nociplastic pain (NP) subtype among low back leg pain (LBLP) patients.

Methods: A retrospective analysis of an LBLP case-control study database was carried out. The presence of NP was assumed if the patient presented with myofascial pain syndrome (MPS) and developed a short-term intensive vasodilatation reaction in the perceived lower leg pain area after provocation by a minimally invasive procedure. Clinical data and standard LBLP diagnostic parameters were analyzed to classify patients as NP (+) vs NP (-). Next, to predict NP probability, logistic regression analysis and a diagnostic classification tree were constructed.

Results: NP was confirmed in $43.75 \%$ of LBLP patients. Women represented $95.24 \%$ of all $\mathrm{NP}(+)$ patients. The diagnostic classification tree indicated that NP was highly probable if the LBLP subject was female and the result of a positive straight leg raise (SLR) test was lower than 45 degrees. If the SLR test result was greater than or equal to 45 degrees, a negative result on the Bragard test would have diagnostic value. This classification tree was approved to a certain extent in the logistic regression model (deviance residuals, min: -1.8519 ; 1Q: -0.5551 ; median: -0.1907 ; 3Q: 0.6565 and max: 2.1058 ) but should be verified in a larger group of subjects.

Conclusion: Female sex, but not clinical data or standard diagnostic parameters, is indicative of nociplastic pain in LBLP patients. More sophisticated statistical methods, based on directly measurable parameters, should be proposed to distinguish NP involvement in LBLP. Keywords: central sensitization, low back pain, nociplastic pain, myofascial pain syndrome, thermovision

\section{Introduction}

Low back-related leg pain (LBLP) is present in $23-57 \%$ of humans suffering from low back pain. ${ }^{1}$ A diagnosis of LBLP is considered if neither radicular pain nor referred pain can be specifically confirmed. ${ }^{2}$ Additionally, the neuropathic pain component in the chronic form of LBLP should be considered in more than $30 \%$ of cases. ${ }^{3}$ Recently, it has been suggested that almost half of chronic low back pain patients present with central sensitization, recently categorized as nociplastic pain. ${ }^{4}$
Correspondence: Elzbieta Skorupska Department of Physiotherapy, Poznan University of Medical Sciences, Smoluchowskiego II, Poznan 60-179, Poland

Tel/Fax +48 6I 83I-02-17

Email skorupska@ump.edu.pl
Journal of Pain Research 2020:13 3427-3435

3427

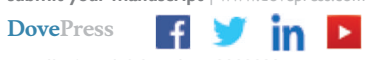

http://doi.org/| 0.2147/IPR.S282233 
Nociplastic pain is defined as altered nociceptive function without any features of a disease or damage of the somatosensory system due to central sensitization (CS) leading to chronic pain. ${ }^{5}$

The clinical characteristic of the central sensitization process is the presence of a series of symptoms, eg, referred pain, widespread pain, tactile allodynia, heightened response to nonnoxious stimuli. ${ }^{6}$ The presence of referred pain similar to sciatica is characteristic of gluteal syndrome, which is typical of chronic pain and has been included in the newest version of the ICD $11 .^{2}$ The prevalence of gluteal syndrome, which is a CS-related subtype of myofascial pain syndrome, has been estimated to occur in approximately $30 \%$ of LBLP patients. ${ }^{7,8}$

Myofascial pain syndrome is defined as a local pain syndrome characterized by (i) the presence of trigger points, ie, limited sites of severe muscle tenderness or hypersensitivity, (ii) a determined area of referred pain, and (iii) characteristic motor, sensory, and autonomic dysfunctions and symptoms. ${ }^{9}$ The location of the referred pain is incompatible with the innervation and dermatomes at the site. However, there is a strong correlation between a given trigger point location and the referred pain. Both trigger point sensitivity and the presence of the referred pain are indicative of central sensitization. ${ }^{10}$ Moreover, the referred pain area grows exponentially as the degree of central sensitization increases. ${ }^{11-13}$

A novel idea for effective pain control is focused on identifying one of the three possible pain mechanisms: nociceptive, neuropathic, or nociplastic. ${ }^{1,14-16}$ Thus, the treatment would follow the pain type. The problem of determining the dominant pain component, however, has not yet been solved. ${ }^{1,14,15}$ To identify patients who present with symptoms related to central sensitization (nociplastic pain), the patient-reported history, questionnaires, and quantitative sensory testing (QST) are recommended. Unfortunately, there is a lack of directly measurable parameters allowing the confirmation of nociplastic pain.

The involvement of the autonomic nervous system (ANS) in the chronic pain region is considered one of the mechanisms leading to CS. The measurement of the ANS response to noxious stimulation in patients with CS is seen as a viable promise for finding an objective parameter that would confirm NP. ${ }^{17}$ A recent study by Nickel et al, ${ }^{18}$ showed that sympathetic function is more related to stimulus intensity than perceived pain intensity. A similar observation was provided in our previous studies on a minimally invasive procedure applied to patients with both LBLP and MPS. ${ }^{7,8}$

A subpopulation of MPS-positive LBLP patients presented with a needle-provoked immediate vascular reaction covering approximately $30 \%$ of the skin of the lower limb within the perceived pain area. Moreover, an average temperature increase of approximately $1^{\circ} \mathrm{C}$ was confirmed, which can be used to visualize the results ${ }^{7,8}$ (video file). The procedure confirms the impairment of blood flow within the pain region due to sympathetic hyperactivity and diminished parasympathetic tone, thus in turn impairing the functioning of the somatosensory nervous system. Based on the objective signs of ANS dysregulation provoked by noxious stimulation that occurs among LBLP patients with gluteal syndrome (recognized as related to central sensitization), we assumed that the patients presented with the nociplastic pain pathomechanism. Since the minimally invasive procedure is difficult to implement clinically and it is difficult for an average physician to confirm gluteal syndrome using the palpatory criteria applied for MPS, we wanted to see if there are any predictable parameters that would facilitate the clinical assessment of NP involvement among LBLP.

The aim of the study was to identify symptoms, signs, and standard diagnostic parameters that would allow predicting the nociplastic pain subtype among LBLP patients.

\section{Method}

The study was conducted in accordance with the Declaration of Helsinki and was approved by the Ethics Committee of Poznan University of Medical Sciences (no. 773/14). All subjects gave written informed consent to participate in the study before data collection. A detailed description of all examination and treatment procedures, including the minimally invasive procedure and risks involved in the study, was provided to the participants. The participants had the right to refuse to undergo the minimally invasive procedure and withdraw from the study at any time without penalty.

Retrospective analysis of the data extracted from previously published trials (ACTRN12614001168640 and ACTRN12614001060639), both supported by the Polish National Science Centre, Grant no. N N404 268,339, was performed. ${ }^{7,8}$ In both studies, LBLP subjects were examined for the presence of MPS using Travell and Simons' standard clinical criteria. The presence of nociplastic pain was assumed if MPS-positive LBLP patients presented with short-term intensive vasodilatation in the perceived 
lower leg pain area after provocation by a minimally invasive procedure. ${ }^{7,8}$

\section{A Short Description of the Minimally Invasive Procedure}

The first step of the evaluation was a side-to-side comparison of the patient's legs at rest. When a decrease of more than $0.5^{\circ} \mathrm{C}$ in the painful area relative to the asymptomatic leg was observed, neuropathic pain was considered possible.

Minimally invasive procedure: Noxious stimulation of the two most sensitive trigger points lasted for 5 mins, each with a 1 min break in between (dry needling of every trigger point within the gluteus minimus muscles). The area of referred pain in the gluteus minimus was registered by an infrared thermovision (IRT) camera. During the whole noxious stimulation, the patients reported the localization of the pain sensation provoked by needling (thigh, calf, foot). The next step of the procedure was IRT observation of the patient at rest for 6 mins (at the region of the referred pain distribution). At the end of the whole procedure, the patient was asked: "Was the pain evoked by needling similar to your daily pain?" A video of the procedure is available in supplementary video S1.

Thermogram analysis: A comparative analysis of the region of interest (ROI), ie, the area of the gluteus minimus referred pain (painful lower leg), was performed. The whole procedure consisted of (1) pre-stimulation phase, (2) stimulation phase, (3) post-stimulation phase, and (4) thermogram analysis. A comparison of temperature changes (minimum, maximum, and average) was conducted and for the first time in medical thermography - the provoked vessel reactions were numerically calculated.

The validation study confirmed that the presence of an isothermal area reflected vasodilatation with a temperature not manifested before the stimulation. Additionally, a significant increase in the average temperature was a significant diagnostic parameter for the MPS confirmation by the minimally invasive procedure. The new isothermal region provoked by the procedure and covering from $5 \%$ to approximately $30 \%$ of the lower limb with a temperature increase above $1.5^{\circ} \mathrm{C}$ was named autonomic referred pain (AURP). The vessel response to the noxious stimulation was exclusive to the location of the gluteus minimus referred pain only.

Thus, two parameters of the minimally invasive procedure, namely a significant increase in the average temperature and AURP from gluteus minimus referred pain of the trigger point, were indicated as diagnostic parameters allowing the confirmation of MPS presence. ${ }^{7}$

\section{Participant Characteristics}

Forty-eight Caucasian patients (mean age $47.5 \pm 8.6 \mathrm{y}$ ) with chronic or subacute (recurrent) LBLP were included in the study (Table 1). The inclusion criteria were as follows: age between 30 and 60, unilateral lower leg, pain duration 1-3 months, leg pain $>3$ on a 1-10 point VAS, and LBLP being the dominant problem. Exclusion criteria: complex regional pain syndrome, cauda equina syndrome, previous back surgery, spinal tumors, scoliosis, pregnancy, coagulant treatment, diabetes, epilepsy, infection, inflammatory rheumatoid diseases, stroke, or oncological history.

Each patient underwent (i) functional examination comprising the straight leg raise test (SLR), cross straight leg raising test (xSLR), passive dorsiflexion test (Bragard), and slump test. Functional tests were performed by two clinicians, and a test was considered positive if confirmed by both; (ii) a 7-step extensive neurological examination including mental status, cranial nerves, motor examination, sensory and reflex examination, coordination and walking (according to a standard neurological protocol); and (iii) magnetic resonance imaging (MRI).

\section{Data Analysis}

Sample size calculation was performed using ENE3.0 and was based on the following schema: 4 features (gender, leg pain localization, MRI, neurological examination) * 2 LBLP categories (NP (+), NP (-)). This sample size would provide $80 \%$ power at the 0.05 alpha level and allow for a $10 \%$ dropout rate. The minimum sample size was established at 40 patients. The level of significance was accepted as $p<0.05$ for all tests. To assess the statistical significance of variables in the NP (+) and NP (-) subgroups, the chi ${ }^{2}$ test for proportions was used. When the p-value of the test was approximately

Table I Baseline Characteristics of Study Participants $(n=48)$

\begin{tabular}{|l|l|}
\hline Data & LBLP \\
\hline Female sex [\%] & 64.6 \\
Age, mean (SD) [y] & $47.5(8.6)$ \\
BMI, mean (SD) & $25.7(4.5)$ \\
Symptoms duration [y] & $5.3(5.7)$ \\
Leg pain above knee [\%] & 36.6 \\
Leg pain below knee [\%] & 63.4 \\
Leg pain below ankle [\%] & 41.5 \\
\hline
\end{tabular}


0.05 or smaller, Fisher's exact test was applied. To assess the significance of differences between numerical parameters in subgroups of subjects, the Mann-Whitney U-test was used. To assess the relation between the variables, we used logistic regression analysis, and we constructed diagnostic classification trees using the "rpart" function. For all statistical analyses, we used the $\mathrm{R}$ free software environment, version 3.5.0.

\section{Results}

\section{Nociplastic Pain Presence}

Nociplastic pain was diagnosed in $43.75 \%$ of LBLP patients (21 out of 48 patients). A total of $64.5 \%$ of LBLP women were NP $(+)$ (20 out of 31 ), while for LBLP men, the value was as low as $5.9 \%$ (1 out of 17$)$; (chi ${ }^{2}$ test for proportions, $\mathrm{p}<0.001 ; 95 \%$ CI $(33.9,83.4)$ ) (Figure 1). When the nociplastic pain subgroups were analyzed, women represented $95.24 \%$ of the total number (Fisher's exact test for contingency tables, $\mathrm{p}<0.001 ; 95 \% \mathrm{CI}(3.61,1343.64))$.

The average VAS score for the whole group was 49.3 $\pm 19.0 \mathrm{~mm}$. NP (+) subjects tended to have a higher VAS value $(54.5 \pm 19.3 \mathrm{~mm})$ than the NP-negative subjects $(45.2$ $\pm 18.0 \mathrm{~mm}$; Mann-Whitney U-test, $\mathrm{p}=0.067,95 \%$ CI $(-22.0,1.00))$. The leg pain localizations for the whole group were as follows: above the knee $36.6 \%$, below the knee $63.4 \%$, below the ankle $41.5 \%$. There was no significant difference between the nociplastic pain-positive and nociplastic pain-negative LBLP patients with regard to leg pain localization.

\section{Functional and Neurological Examination}

The neurological examination confirmed a clear tendency towards impairment of the L5 temperature sensation (chi ${ }^{2}$ test for proportions, $\mathrm{p}=0.063 ; 95 \% \mathrm{CI}(-2,42))$. We also used Fisher's exact test for contingency tables and obtained an even smaller $\mathrm{p}=0.03$ and a $95 \% \mathrm{CI}$ for the ratio of proportions of ( 0.93 , infinity). There was no difference between the subgroups concerning mental status, cranial nerves, motor examination, the Romberg test and walking tests. The results of the functional examination for the whole group were as follows: $\mathrm{SLR} \leq 45^{\circ} 43.8 \%$; SLR $>45^{\circ} 56.3 \%$; xSLR $2.1 \%$; Bragard test 50\%; slump test $27.1 \%$; Bragard and slump test (both positive) $20.8 \%$. The impairments in the sensory testing results for the whole group were as follows: pinprick L2 4.3\%; L3 8.3\%; L4 20.8\%; L5 14.6\%; S1 8.3\%, temperature L2 2.2\%; L5 8.7\%; S1 2.2\%. Vibratory sensation impairment was not confirmed. The results of the tendon reflex examination for the whole group were as follows: impaired patellar 35.4\%; impaired Achilles 58.3\%; absent patellar 0\%; absent Achilles $18.8 \%$. Pain over the lumbar spinous processes was confirmed in $19.6 \%$ of LBLP patients.

\section{Magnetic Resonance Imaging}

The chi ${ }^{2}$ test for proportions did not reveal any significant differences in the MRI results. The results for the whole group were as follows: root compression L4 16.7\%; L5 $25.0 \%$; S1 22.9\%, disc prolapse L3-L4 27.1\%; L4-L5 $54.2 \%$; L5-S1 $58.3 \%$. LBLP and leg pain localization, distribution data for LBLP patients positive and negative

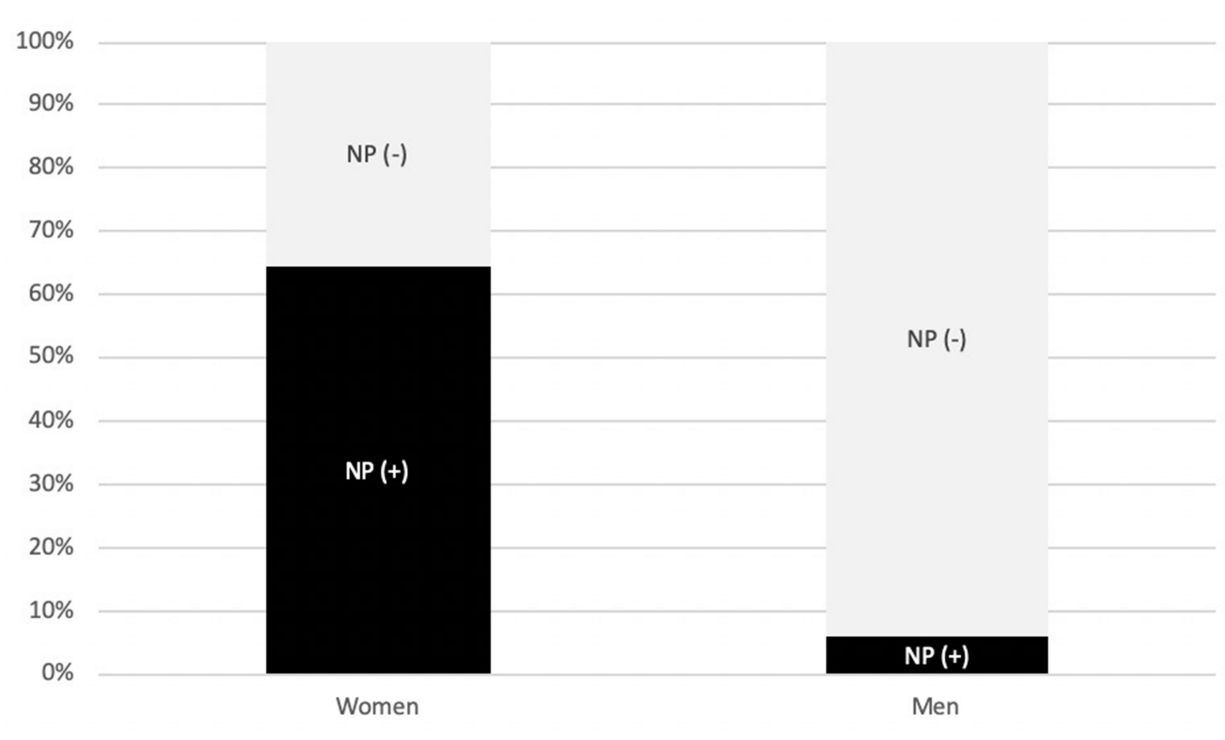

Figure I Gender proportion for patients positive and negative for nociplastic pain (NP). 
for nociplastic pain and magnetic resonance imaging results are shown in Table 2.

\section{Predictors for NP Among LBLP Subjects}

Based on the sample size and statistical estimation, our main goal was to develop a simple algorithm for identifying NP, which is why we chose to conduct logistic regression analysis and then present our results as a classification tree. According to the classification tree results, nociplastic pain is highly probable if the LBLP subject is female and the result of a positive SLR test is lower than 45 degrees. If the SLR test result is higher than or equal to 45 degrees, a negative Bragard test result will have diagnostic value. However, it is not clear if a positive Bragard test result excludes the probability of NP (Figure 2).

This combination of variables (gender, Bragard test result, and SLR) showed that they were all important in the logistic regression analysis; individually, the most

Table 2 Clinical Data and Standard LBLP Diagnostic Parameter Distribution for Patients Positive and Negative for Nociplastic Pain

\begin{tabular}{|c|c|c|c|c|}
\hline \multicolumn{2}{|l|}{ Positive Results } & \multicolumn{3}{|c|}{ Number and Percentage of LBLP Subjects (\%) } \\
\hline & & \multirow{2}{*}{$\begin{array}{l}\text { NP (+) Patients } \\
\mathbf{n = 2} \text { I } \\
9(44.4) \\
12(55.6) \\
10(50)\end{array}$} & \multirow{2}{*}{$\begin{array}{l}\text { NP (-) Patients } \\
\mathbf{n}=\mathbf{2 7} \\
8(30.4) \\
19(69.6) \\
10(34.8)\end{array}$} & \multirow{2}{*}{$\begin{array}{l}\text { p-value and } 95 \% \text { and } \mathrm{Cl}\left(\mathrm{chi}^{2} \text { Test for }\right. \\
\text { Proportions) } \\
0.53 \mathrm{Cl}(-20.6,48.6) \\
0.53 \mathrm{Cl}(-48.6,20.6) \\
0.5 \mathrm{I} \mathrm{Cl}(-19.9,50.4)\end{array}$} \\
\hline Leg pain location & $\begin{array}{l}\text { Above knee } \\
\text { Below knee } \\
\text { Below ankle }\end{array}$ & & & \\
\hline $\begin{array}{l}\text { Functional } \\
\text { examination }\end{array}$ & $\begin{array}{l}\text { SLR } \leq 45^{\circ} \\
\text { SLR }>45^{\circ} \\
x S L R \\
\text { Bragard }(+) \\
\text { Slump }(+) \\
\text { Bragard and Slump }(+)\end{array}$ & $\begin{array}{l}\text { II }(52.5) \\
10(47.5) \\
0 \\
8(38.1) \\
5(23.8) \\
2(9.5)\end{array}$ & $\begin{array}{l}10(37) \\
17(63) \\
1(3.7) \\
16(59.2) \\
8(29.6) \\
8(29.6)\end{array}$ & $\begin{array}{l}0.4 \mathrm{ICl}(-17.0,47.6) \\
0.4 \mathrm{ICl}(-47.6,16.7) \\
0.95 \mathrm{Cl}(-4.5,7.1) \\
0.24 \mathrm{Cl}(-53.2,10.9) \\
0.87 \mathrm{Cl}(-35.1,23,5) \\
0.19 \mathrm{Cl}(-45.7,5.4)\end{array}$ \\
\hline Pinprick & $\begin{array}{l}\text { L2 } \\
\text { L3 } \\
\text { L4 } \\
\text { L5 } \\
\text { SI }\end{array}$ & $\begin{array}{l}\text { I }(5) \\
\text { I (4.8) } \\
6(28.6) \\
2(9.5) \\
\text { I }(4.8)\end{array}$ & $\begin{array}{l}1(3.7) \\
3(11.1) \\
4(14.8) \\
5(18.5) \\
3(11.1)\end{array}$ & $\begin{array}{l}0.98 \mathrm{Cl}(-|\mathrm{I} .6,| \mathrm{I} .7) \\
0.77 \mathrm{Cl}(-25.5, \mid \mathrm{I} .8) \\
0.4 \mathrm{ICl}(-|4,4| .5) \\
0.65 \mathrm{Cl}(-32.5, \mid 14.5) \\
0.75 \mathrm{Cl}(-25.5, \mid 2.8)\end{array}$ \\
\hline $\begin{array}{l}\text { Temperature } \\
\text { impairment }\end{array}$ & $\begin{array}{l}\text { L2 } \\
\text { L3 } \\
\text { L4 } \\
\text { L5 } \\
\text { SI }\end{array}$ & $\begin{array}{l}0 \\
0 \\
0 \\
4(20) \\
0\end{array}$ & $\begin{array}{l}\mathrm{I}(3.8) \\
0 \\
0 \\
0 \\
\mathrm{I}(3.8)\end{array}$ & $\begin{array}{l}\mathrm{I} .00 \mathrm{Cl}(-14.5,7.1) \\
\mathrm{NA} \\
\mathrm{NA} \\
0.06 \mathrm{Cl}(-2,42) \\
\mathrm{I} \mathrm{Cl}(-14.5,7.1)\end{array}$ \\
\hline \multicolumn{2}{|c|}{ Vibratory sensation impairment } & 0 & 0 & NA \\
\hline Tendon reflex & $\begin{array}{l}\text { Patellar impaired } \\
\text { Patellar absent } \\
\text { Achilles impaired } \\
\text { Achilles absent }\end{array}$ & $\begin{array}{l}7(33.3) \\
0 \\
\text { II (52.4) } \\
5(23.8)\end{array}$ & $\begin{array}{l}10(37) \\
0 \\
17(63) \\
4(14.8)\end{array}$ & $\begin{array}{l}\mathrm{I} C l(-34.6,27.2) \\
\mathrm{NA} \\
0.65 \mathrm{Cl}(-42.9,21.7) \\
0.66 \mathrm{Cl}(-17.9,35.8)\end{array}$ \\
\hline \multicolumn{2}{|c|}{ Pain over the lumbar spinous processes } & $5(25)$ & $4(15.4)$ & $0.66 \mathrm{Cl}(-18.3,37.5)$ \\
\hline Root compression & $\begin{array}{l}\text { L4 } \\
\text { L5 } \\
\text { SI }\end{array}$ & $\begin{array}{l}2(9.5) \\
7(33.3) \\
6(28.6)\end{array}$ & $\begin{array}{l}6(22.2) \\
5(18.5) \\
5(18.5)\end{array}$ & $\begin{array}{l}0.40 \mathrm{Cl}(-0.37,0.12) \\
0.34 \mathrm{Cl}(-0.33,0.19) \\
0.6 \mathrm{Cl}(-0.18,0.39)\end{array}$ \\
\hline Disc prolapse & $\begin{array}{l}\text { L3-L4 } \\
\text { L4-L5 } \\
\text { L5-SI }\end{array}$ & $\begin{array}{l}7(33.3) \\
\text { II }(52.4) \\
13(61.9)\end{array}$ & $\begin{array}{l}6(22.2) \\
15(55.6) \\
15(55.6)\end{array}$ & $\begin{array}{l}0.57 \mathrm{Cl}(-0.19,0.4 \mathrm{I}) \\
0.99 \mathrm{Cl}(-0.35,0.28) \\
0.86 \mathrm{Cl}(-0.26,0.39)\end{array}$ \\
\hline
\end{tabular}

Abbreviations: SLR, straight leg test; xSLR, cross straight leg test; NP, (+) nociplastic pain positive; NP, (-) nociplastic pain negative; NA, not applicable. 


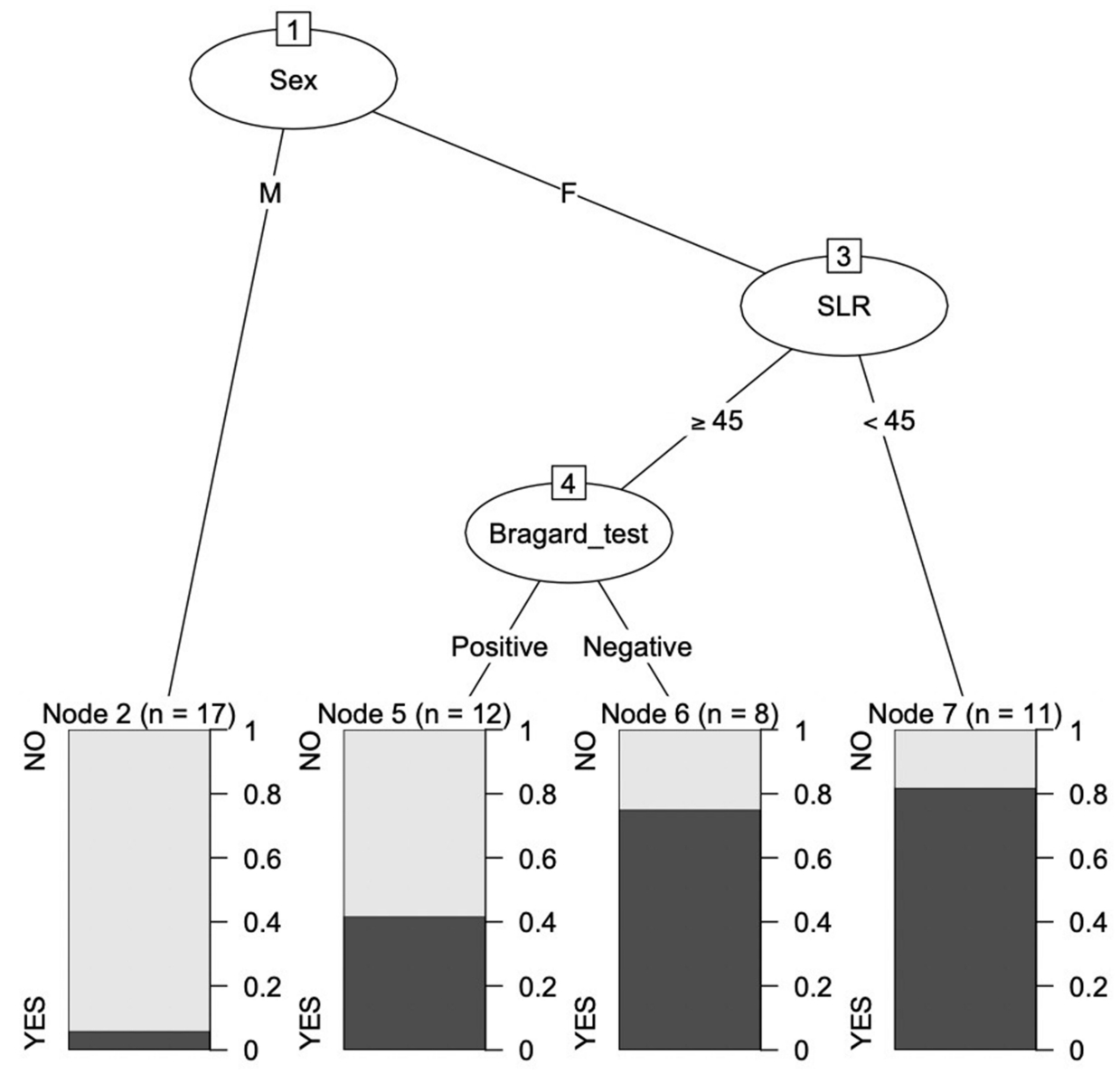

Figure 2 Proposal of predictors for NP presence among LBLP subjects.

significant variable was gender, followed by the Bragard test result and SLR (Figure 3). The deviance residuals were $\min -1.8519$; 1Q -0.5551 ; median -0.1907 ; 3Q 0.6565 ; and max: 2.1058 .

The classification tree was approved to a certain extent by the logistic regression model, but it should not be considered fully reliable because it needs to be verified in a larger group of subjects. We also added the VAS score as a variable in our analysis, but after incorporating it into the above two models, we could not show that it had any significance when combined with the other model variables.

\section{Discussion}

Female sex was revealed as the parameter most indicative of the presence of nociplastic pain among LBLP patients ( $p$ $<0.001$ ); $95.24 \%$ of NP (+) patients were female in this cohort. Additionally, pain severity $(\mathrm{p}=0.067)$ and L5 temperature impairment $(\mathrm{p}=0.06)$ were almost significant. It is known that the female gender predisposes the individual to diseases resulting from central sensitization, such as fibromyalgia or chronic pain. ${ }^{19}$ However, there have been no data that would support this predisposition for LBLP patients. Generally, it is agreed that men and women differ in their responses to pain, with increased pain sensitivity and risk of clinical pain occurrence among women. Although the etiological basis underlying these sex differences is unknown, one should take into account hormone status. ${ }^{20-23}$ Moreover, female predisposition to the asymptomatic form of MPS in the lower limbs has been confirmed. ${ }^{24}$ Thus, one has to assume that nociplastic pain may result from the response to a prolonged LBLP or can develop due to mechanical posture overloading or muscle involvement during the acute phase of disc disease.

The clinical utility of conventional examinations, extensive neurological examination, functional tests, and MRI results in distinguishing nociplastic pain related to myofascial pain syndrome among LBLP patients was not demonstrated. None of the parameters, apart from the L5 


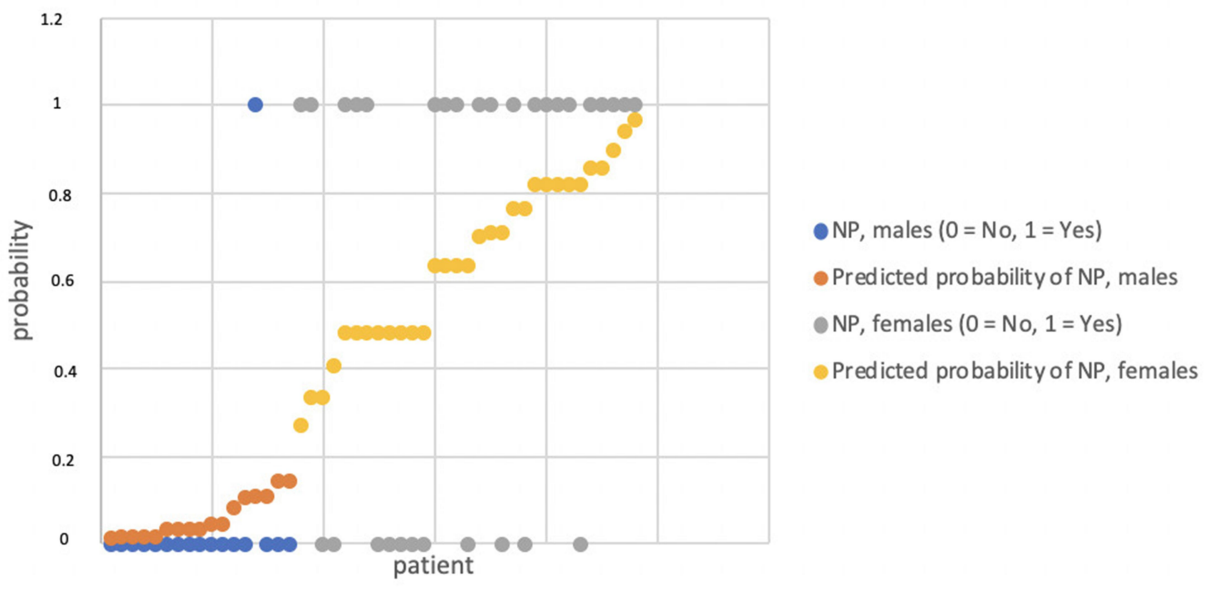

Figure 3 Probabilities of NP among LBLP subjects predicted by the logistic regression model.

temperature sensory thresholds and VAS pain severity (with tendency to significance), were indicative of nociplastic pain. Currently, the self-reported Central Sensitization Inventory (CSI) questionnaire and the examination of sensory disturbances, eg, quantitative sensory testing (QST), are used to diagnose central sensitization. The relevance of the sensory disturbance examination to the referred pain of asymptomatic MPS patients as measured by QST has been confirmed. ${ }^{25}$ Thus, a precise sensory examination, eg, using QST versus a minimally invasive procedure for $\mathrm{CS}$ involvement, is required for LBLP.

Nevertheless, neither method can be easily implemented in clinical practice. The results of the current study suggest the relevance of specific parameters. It seems clinically important to determine whether a more sophisticated statistical method allows predicting the presence of CS without the need to perform QST or register the ANS response to noxious stimuli. Thus, we proposed a decision tree method. To exemplify this idea, for the purpose of future studies, we built an example of a decision tree based on the current study sample (Figure 2). Nociplastic pain is highly probable if the LBLP subject is female and the result of a positive SLR test is lower than 45 degrees. If the SLR test result is higher than or equal to 45 degrees, a negative result on the Bragard test will have diagnostic value. However, it is not clear if a positive Bragard test result excludes the probability of NP. The logistic regression model (Figure 3) confirmed the presented classification tree to a certain extent, but the tree should be verified in a larger group of subjects because of its limited reliability.
The classification tree underlines the importance of functional tests. These tests are widely considered neurotension tests that can suggest the origin of radicular pain. However, false-positive results in cases not specific to lumbar radiculopathy but presenting muscle tightness have been indicated as a possible factor that may inflate the sensitivity of the SLR test. MPS syndrome affects a group of muscles via key trigger points followed by satellite trigger points. Marinho et $\mathrm{al}^{26}$ demonstrated the physiological soft tissue continuity between the hip and the ankle joint. Based on this, we can assume that positive SLR results among LBLP patients presenting with gluteal syndrome are due to muscle rather than neural tension. A positive SLR result is mentioned as a sign of gluteal syndrome in the ICD 11. It seems that a detailed SLR examination could demonstrate a specific painexacerbating angle of the leg raise. ${ }^{27}$ The cluster comprising a negative Bragard test result and an SLR result greater than 45 degrees can be hypothetically explained as the provocation of sensation due to muscle shortening, which can be misinterpreted as sciatic nerve irritation. Some authors previously suggested that a positive SLR test can result from "tight hamstring syndrome", characterized by the tightness of the lumbar and ischiocrural muscles. $^{28}$

Further studies should be conducted to obtain a more precise definition involving a cluster of signs, symptoms, and clinical parameters for predicting NP.

\section{Clinical Relevance}

The clinical importance of the study is that $30 \%$ of LBLP patients, mostly women, require a specific therapeutic 
approach that should consider the gluteus minimus as a potential pain treatment area. This is in accordance with the International Association of the Study of Pain (IASP) recommendation about different treatment strategies depending on the pain mechanism.

Second, the proposed cluster of symptoms and signs indicative of NP among LBLP patients seems interesting and valuable for future studies that could involve a greater number of patients. Hypothesis-testing studies followed by both narrow and broad validation studies, and finally, studies testing the capacity of subgrouping for routine clinical care are recommended. ${ }^{29,30}$

\section{Study Limitations}

The results of our study were limited by the lack of the CSI questionnaire. However, a minimally invasive procedure, which revealed autonomic nervous system involvement in perceived LBLP if the patient is MPS positive, seems much more valuable for somatosensory nervous system impairment.

Summary: Female gender, but not clinical data or standard diagnostic parameters, is indicative of nociplastic pain among LBLP patients. More sophisticated statistical methods, eg, classification trees based on the minimally invasive procedure, should be proposed to distinguish nociplastic pain involvement in LBLP.

\section{Abbreviations}

Low back leg pain, LBLP; central sensitization, CS; myofascial pain syndrome, MPS; quantitative sensory testing, QST; straight leg raise, SLR; cross straight leg raising, xSLR; magnetic resonance imaging, MRI; central Sensitization Inventory, CSI.

\section{Acknowledgments}

Prof. Tomasz Kotwicki for assisting with the first revision of the manuscript.

\section{Disclosure}

No significant financial support was provided for this work that could have influenced its outcome. The authors report no conflicts of interest in this work.

\section{References}

1. Schafer A, Hall T, Briffa K. Classification of low back-related leg pain - a proposed patho-mechanism-based approach. Man Ther. 2009;14(2):222-230. doi:10.1016/j.math.2007.10.003
2. https://www.iasp-pain.org/PublicationsNews/Content.aspx? ItemNumber $=1673 \&$ navItemNumber $=677$. Accessed October.30, 2020.

3. Fishbain DA, Cole B, Lewis JE, Gao J. What is the evidence that neuropathic pain is present in chronic low back pain and soft tissue syndromes? An evidence-based structured review. Pain Med. 2014;15(1):4-15. doi:10.1111/pme.12229

4. Aoyagi K, He J, Nicol AL, et al. A subgroup of chronic low back pain patients with central sensitization. Clin J Pain. 2019;35 (11):869-879. doi:10.1097/AJP.0000000000000755

5. Trouvin AP, Perrot S. New concepts of pain. Best Pract Res Clin Rheumatol. 2019;33(3):101415. doi:10.1016/j.berh.2019.04.007

6. Woolf CJ. Central sensitization: implications for the diagnosis and treatment of pain. Pain. 2011;152(Supplement):S2-S15. doi:10.1016/ j.pain.2010.09.030

7. Skorupska E, Rychlik M, Samborski W. Validation and test-retest reliability of new thermographic technique called thermovision technique of dry needling for gluteus minimus trigger points in sciatica subjects and TrPs-negative healthy volunteers. Biomed Res Int. 2015;2015:546497. doi:10.1155/2015/546497

8. Skorupska E, Rychlik M, Samborski W. Intensive vasodilatation in the sciatic pain area after dry needling. BMC Complement Altern Med. 2015;15:72. doi:10.1186/s12906-015-0587-6

9. Travell JG, Simons DG. Myofascial Pain and Dysfunction: The Trigger Point Manual. Baltimore, Md, USA: Williams \& Wilkins; 1983.

10. Arendt-Nielsen L, Graven-Nielsen T. Central sensitization in fibromyalgia and other musculoskeletal disorders. Curr Pain Headache Rep. 2003;7(5):355-361. doi:10.1007/s11916-003-0034-0

11. Mense S, Gerwin RD, editors. Muscle Pain: Understanding the Mechanisms. Berlin: Springer-Verlag; 2010.

12. Fernández-de-las-Peñas $\mathrm{C}$, Schoenen J. Chronic tension type headache: what's new? Curr Opin Neurol. 2009;22:254-261. doi:10.1097/ WCO.0b013e32832973ce

13. Arendt-Nielsen L, Svensson P. Referred muscle pain: basic and clinical findings. Clin J Pain. 2001;17(1):11-19. doi:10.1097/ 00002508-200103000-00003

14. Smart KM, Blake C, Staines A, Thacker M, Doody C. Mechanismsbased classifications of musculoskeletal pain: part 1 of 3: symptoms and signs of central sensitization in patients with low back ( \pm leg $)$ pain. Man Ther. 2012;17(4):336-344. doi:10.1016/j.math.2012.03.013

15. Smart KM, Blake C, Staines A, Thacker M, Doody C. Mechanismsbased classifications of musculoskeletal pain: part 3 of 3: symptoms and signs of nociceptive pain in patients with low back ( \pm leg) pain. Man Ther. 2012;17(4):352-357. doi:10.1016/j.math.2012.03.002

16. Nijs J, Torres-Cueco R, van Wilgen CP, et al. Applying modern pain neuroscience in clinical practice: criteria for the classification of central sensitization pain. Pain Physician. 2014;17(5):447-457.

17. Ansuategui Echeita J, Schiphorst Preuper HR, Dekker R, et al. Central Sensitisation and functioning in patients with chronic low back pain: protocol for a cross-sectional and cohort study. BMJ Open. 2020;10(3):e031592. doi:10.1136/bmjopen-2019-031592

18. Nickel MM, May ES, Tiemann L, Postorino M, Ta Dinh S, Ploner M. Autonomic responses to tonic pain are more closely related to stimulus intensity than to pain intensity. Pain. 2017;158:2129-2136. doi:10.1097/j.pain.0000000000001010

19. Smith MT Jr, Remeniuk B, Finan PH, et al. Sex differences in measures of central sensitization and pain sensitivity to experimental sleep disruption: implications for sex differences in chronic pain. Sleep. 2019;42(2). doi:10.1093/sleep/zsy209.

20. Chen CK, Nizar AJ. Myofascial pain syndrome in chronic back pain patients. Korean J Pain. 2011;24(2):100-104. doi:10.3344/ kjp.2011.24.2.100

21. Bartley EJ, Fillingim RB. Sex differences in pain: a brief review of clinical and experimental findings. Br J Anaesth. 2013;111(1):52-58. doi:10.1093/bja/aet127 
22. Basford JR, An KN. New techniques for the quantification of fibromyalgia and myofascial pain. Curr Pain Headache Rep. 2009;13 (5):376-378. doi:10.1007/s11916-009-0061-6

23. Severino SK, Moline ML. Premenstrual syndrome. Obstet Gynecol Clin North Am. 1990;17(4):889-903.

24. Zuil-Escobar JC, Martinez-Cepa CB, Martin-Urrialde JA, GomezConesa A. The prevalence of latent trigger points in lower limb muscles in asymptomatic subjects. PM R. 2016;8(11):1055-1064. doi:10.1016/j.pmrj.2016.03.005

25. Ambite-Quesada S, Arias-Buria JL, Courtney CA, Arendt-Nielsen L, Fernandez-de-Las-Penas C. Exploration of quantitative sensory testing in latent trigger points and referred pain areas. Clin J Pain. 2018;34(5):409-414. doi:10.1097/AJP.0000000000000560

26. Marinho HVR, Amaral GM, Moreira BS, et al. Myofascial force transmission in the lower limb: an in vivo experiment. $J$ Biomech. 2017;63:55-60. doi:10.1016/j.jbiomech.2017.07.026
27. Scaia V, Baxter D, Cook C. The pain provocation-based straight leg raise test for diagnosis of lumbar disc herniation, lumbar radiculopathy, and/or sciatica: a systematic review of clinical utility. $J$ Back Musculoskelet Rehabil. 2012;25(4):215-223. doi:10.3233/BMR2012-0339

28. Atalay A, Akbay A, Atalay B, Akalan N. Lumbar disc herniation and tight hamstrings syndrome in adolescence. Childs Nerv Syst. 2003;19 (2):82-85. doi:10.1007/s00381-003-0716-2

29. McGinn TG, Guyatt GH, Wyer PC, Naylor CD, Stiell IG, Richardson WS. Users' guides to the medical literature: XXII: how to use articles about clinical decision rules. Evidence-based medicine working group. JAMA. 2000;284(1):79-84. doi:10.1001/jama.284.1.79

30. Kent P, Keating JL, Leboeuf-Yde C. Research methods for subgrouping low back pain. BMC Med Res Methodol. 2010;10:62. doi:10.1186/1471-2288-10-62

\section{Publish your work in this journal}

The Journal of Pain Research is an international, peer reviewed, open access, online journal that welcomes laboratory and clinical findings in the fields of pain research and the prevention and management of pain. Original research, reviews, symposium reports, hypothesis formation and commentaries are all considered for publication. The manuscript management system is completely online and includes a very quick and fair peer-review system, which is all easy to use. Visit http:// www.dovepress.com/testimonials.php to read real quotes from published authors. 